\title{
The Use of Immunohistochemistry for Diagnosis of Prostate Cancer
}

\author{
Katia R. M. Leite, Miguel Srougi, Adriana Sanudo, Marcos F. Dall'oglio, Adriano Nesrallah, \\ Alberto A. Antunes, Jose Cury, Luiz H. Camara-Lopes
}

Laboratory of Medical Investigation (KRML, MS, AS, MFDO, AN, AAA, JC), Division of Urology, University of Sao Paulo Medical School, and Genoa Biotechnology (KRML, LHCL), Sao Paulo, Brazil

\begin{abstract}
Purpose: Atypical glands (ASAP) are diagnosed in 5.0\% of prostate biopsies, and cancer identification in a rebiopsy is higher than $40.0 \%$. The use of antibodies to mark basal cells is currently a common practice, in order to avoid rebiopsies. There has been no reported study that has reviewed characteristics of radical prostatectomies (RPs) when immunohistochemistry (IHC) was necessary for definitive diagnosis.

Materials and Methods: Out of 4127 biopsies examined from 2004 to 2008, 144 (3.5\%) were diagnosed with ASAP. IHC was performed using antibody anti-34ßE12 and p63. The results of surgical specimens of 27 patients treated by RP after the diagnosis of prostate cancer (PC) was made using IHC (Group 1) were compared with 1040 patients where IHC was not necessary (Group 2).

Results: IHC helped to diagnose PC in 103 patients (71.5\%). Twenty-seven (26.2\%) underwent RP. In Group 1, two (7.4\%) adenocarcinomas were insignificant versus 29 (2.9\%) for Group 2. Patients from Group 1 were younger $(p=0.039)$, had lower Gleason scores (GS) $(p<0.001)$, lower percentage of Gleason pattern $4(p<0.001)$, and smaller tumors $(p<0.001)$.

Conclusion: The use of IHC did not lead to diagnosis of insignificant tumors as illustrated by absence of differences in pathological stage or positive surgical margins in men submitted to RP. Therefore, our results suggest that this modality should be routinely used for a borderline biopsy and ASAP cases.
\end{abstract}

Key words: prostatic neoplasms; diagnosis; biopsy; immunohistochemistry; atypical small acinar proliferation Int Braz J Urol. 2010; 36: 583-90

\section{INTRODUCTION}

Atypical glands suspicious for carcinoma, also denominated atypical small acinar proliferation (ASAP), is not a specific entity but represents a large group of lesions which includes lesions that mimic cancer and, most importantly, carcinomas that lack all the cytological and/or architectural characteristics for the establishment of a definitive diagnosis of cancer.
The frequency of this diagnosis is variable from 0.7 to $23.4 \%$, with a mean of $5.0 \%$, as reviewed by Epstein and Herawi (1). The possibility of diagnosing cancer in a subsequent biopsy is high, mean $40.2 \%$ (1-3). After radical prostatectomy (RP), the majority of cases are determined to be low grade and organ-confined $(2,4,5)$.

In 1984, Gown and Vogel (6) reported the use of a monoclonal antibody anti-high molecular weight 
cytokeratin (34ßE12) to mark basal cells of the prostate that was later demonstrated as a characteristic of benign glands that retain the basal cell layer (7-9). In a larger series, Wojno and Epstein (10) used 34ßE12 to diagnose adenocarcinoma in suspicious glands identified in needle prostate biopsies. Shah et al. (11) later proposed the combined use of p63, an homolog of the p53 tumor suppressor protein, as an auxiliary for the determination of cancer since it is also a protein expressed selectively by the basal cells of epithelial organs, including the prostate gland $(12,13)$.

Recently, lower levels of prostate specific antigen (PSA) have been used to indicate the need for a prostate biopsy, and there has been an increasing number of cores taken in each biopsy session. These new practices have resulted in the representation of smaller tumors, often more adequately named ASAP. In addition, pathologists frequently use immunohistochemistry to enhance their diagnostic capabilities in order to avoid rebiopsies. There have been reports of false-positives and false-negatives for use of the combined 34ßE12 and p63 cocktail. To date there has been no reported study that reviews surgical specimens of tumors from patients who underwent $\mathrm{RP}$ after a diagnosis of carcinoma in which the use of immunohistochemistry was necessary for the definitive diagnosis.

\section{MATERIALS AND METHODS}

From January $1^{\text {st }} 2004$ to July $31^{\text {st }} 2008,4127$ biopsies were examined in our laboratory. ASAP was the diagnosis made for 144 (3.5\%) of the biopsies. The mean age of the patients was 60.8 years old, median 60 ranging from 40 to 84 years old. Mean PSA was $7.11 \mathrm{ng} / \mathrm{mL}$, with a median of $5.3 \mathrm{ng} / \mathrm{mL}$, ranging from 1.4 to $43.5 \mathrm{ng} / \mathrm{mL}$. The free to total relation of PSA was mean $15.1 \%$, median $13.0 \%$, ranging from 1 to $30 \%$. The major reason for a biopsy among these patients was a progressive increase in PSA levels. One patient had a familiar history, and two had shown abnormalities in transrectal examination. In 31 patients (21.5\%), ultrasound examination found abnormalities, hypoecoic and hypervascular areas. Twenty patients $(13.9 \%)$ had previously undergone biopsies. The mean number of cores taken per biopsy session was 15.8 , median 14, ranging from 6 to 40. All the slides were examined by the same uropathologist.

The immunohistochemistry was performed using a mouse monoclonal antibody anti-high molecular weight cytokeratin (clone 34ßE12, Dako, Glostrup, Denmark) at a dilution of 1/100 and p63 (clone 4A4, Dako, Glostrup, Denmark) at a dilution of $1 / 100$. After paraffin removal and hydration, the slides were immersed in $10 \mathrm{mM}$ citrate buffer $\mathrm{pH}$ 6 , for $15 \mathrm{~min}$ for antigen retrieval. The antibodies were incubated overnight at $4^{\circ} \mathrm{C}$, and the secondary biotin-labeled antibody was incubated for $30 \mathrm{~min}$ at room temperature. The streptavidin labeled streptavidin-biotin amplification method (Dako K0679) was carried out for 30 minutes followed by peroxidase/diaminobenzidine substrate/chromagen. The slides were counterstained with hematoxylin.

RP was carried out in 27 out of 144 patients. The results were compared to 1040 patients who underwent RP during the same period and where the histology was sufficient to define adenocarcinoma. All patients were treated by the same group of surgeons. The surgical specimens were routinely examined in toto by the same pathologist. To measure tumor volume we used the grid method as described by Humphrey and Vollmer (14).

\section{RESULTS}

Immunohistochemistry permitted the definitive diagnosis of prostate cancer in 103 patients $(71.5 \%)$ (Figure-1). The mean age of patients was 61.7 years old, median 61 (range 43 - 84); mean PSA was $7.6 \mathrm{ng} / \mathrm{mL}$, median $5.4 \mathrm{ng} / \mathrm{mL}$ (range 1.4 - 44 $\mathrm{ng} / \mathrm{mL}$ ); and PSA free to total ratio was mean $15 \%$, median 13\% (range 1 - 29\%). The mean Gleason score was 5.9, median 6 (range 4 to 7 ). The mean and median number of cores positive for tumor was 1.4 and 1 respectively, ranging from 1 to 4 . The higher percentage of a single core that made up the tumor was mean $18.3 \%$, median $10 \%$ (range 1 to $80 \%$ ). The mean total percentage of tumor in all cores was $1.6 \%$, median $1 \%$ (range 1 to $7 \%$ ). Perineural invasion was not detected in any cases.

We had access to the surgical specimens from $27(26.2 \%)$ patients who underwent radical prostatec- 

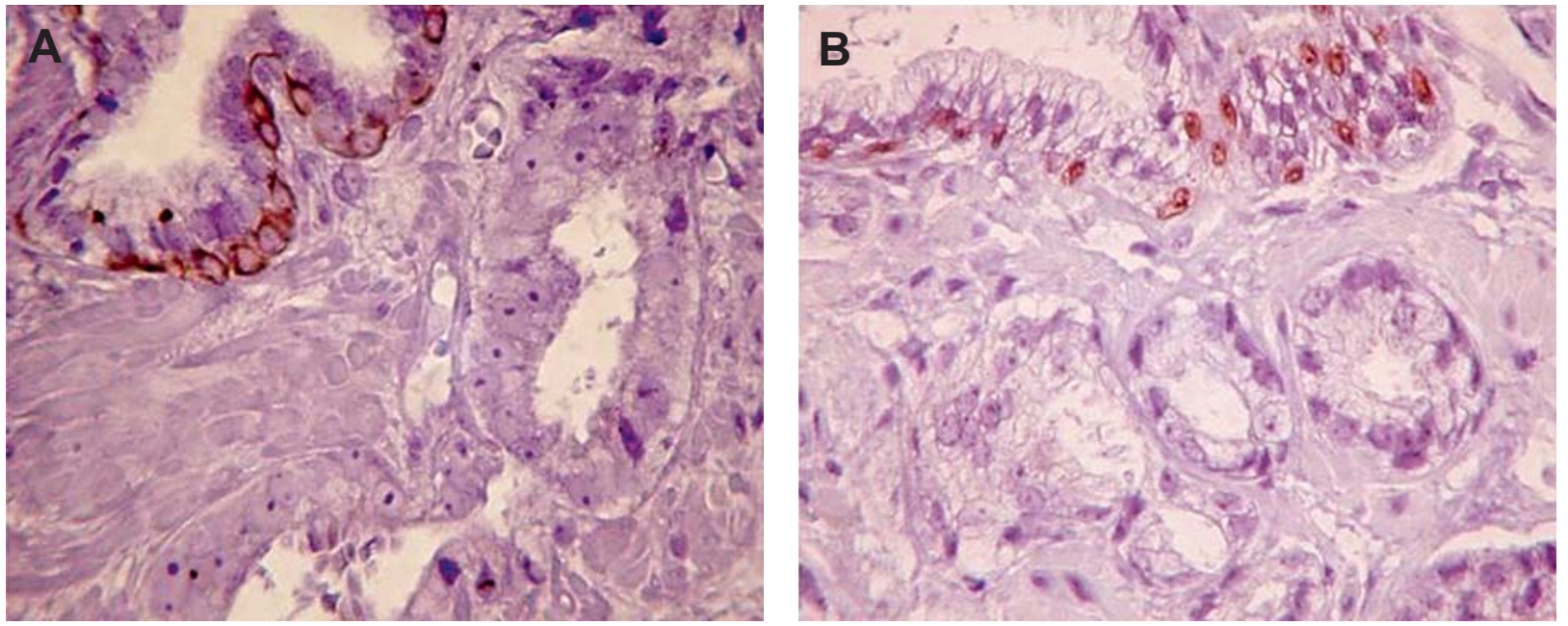

Figure 1 - Immunohistochemistry study of prostate biopsy with atypical small acinar proliferation, where a diagnosis of adenocarcinoma was made because of the absence of basal cells in the neoplastic glands. A normal gland is represented at the top of the figure with basal cells stained by antibodies anti-high molecular weight cytokeratin $34 \beta E 12$ (A) and anti-p63 (B).

tomy. For the same period, from January 12004 to July 31 2008, 1040 patients also underwent radical prostatectomy after a diagnosis of adenocarcinoma that did not necessitate immunohistochemistry for the final diagnosis. The former will be referred to as Group 1, and the control group as Group 2. The characteristics of both groups are shown in Table-1. There were no pT0 in any of the two groups. Within Group

Table 1 - Demographic description and tumor characteristics of patients submitted to radical prostatectomy for treatment of prostate cancer. Group 1 represents patients where immunohistochemistry was used for the definitive diagnosis. Group 2 represents patients where the diagnosis was made without any complementary study.

\begin{tabular}{lccc}
\hline & $\begin{array}{c}\text { Group 1 } \\
(27)\end{array}$ & $\begin{array}{c}\text { Group 2 } \\
(1040)\end{array}$ & p Value \\
\hline Age years old & 56 & 61 & 0.039 \\
Median (Q1 - Q3) & $(53-65)$ & $(55-67)$ & $<0.001$ \\
Gleason Score & 6 & 7 & \\
Median (Q1 - Q3) & $(6-6)$ & $5-7)$ & $<0.001$ \\
\% of pattern 4 of Gleason & 0 & $(9-100)$ & $<0.001$ \\
Median (Q1 - Q3) & $(0-17.75)$ & 11 & \\
Tumor volume \% & 3 & $(6-18)$ & 0.089 \\
Median (Q1 - Q3) & $(2.5-8.0)$ & $824(79.2 \%)$ & \\
Stage & & $216(20.8 \%)$ & 0.801 \\
$\quad$ pT2 & $25(92.6 \%)$ & $253(24.3 \%)$ & \\
pT3 & $2(7.4 \%)$ & & \\
Positive surgical margins & $6(22.2 \%)$ & & \\
\hline
\end{tabular}


1, two (7.4\%) adenocarcinomas could be considered clinically insignificant, defined as less than $2 \%$ of the gland involved, organ-confined and with no Gleason 4 or 5 pattern present, versus 29 (2.9\%) insignificant cases in Group 2 (15).

The patients in Group 1 were younger, had lower Gleason scores, a lower percentage of Gleason pattern 4 and smaller tumors. However, the rate of positive surgical margins was similar and there were no differences in pathological stage.

\section{COMMENTS}

The use of IHC as an auxiliary in the diagnosis of adenocarcinoma is a common practice in uropathology, and the use of antibodies against p63 and high molecular weight cytokeratin has been recommended as adjuncts in confirming prostatic carcinoma in doubtful cases.

Although basal cell markers, such as $34 \beta \mathrm{E} 12$ and $\mathrm{p} 63$ antibodies are useful for identifying basal cells, several benign mimickers of PC, such as atrophy, atypical adenomatous hyperplasia, nephrogenic adenoma, and mesonephric hyperplasia, can stain negatively with these markers. In addition, with patients being submitted to prostate biopsy with lower PSA levels and with larger numbers of cores being taken in each biopsy session, concern that patients are being overtreated is common.

Our results show that there was no overdiagnosis of $\mathrm{PC}$ with any $\mathrm{pT} 0$ after radical prostatectomy, with only $7.4 \%$ of cases classified as clinically insignificant. Tumor stage was similar for both groups, but only $7.4 \%$ of patients from Group 1 had stage pT3 tumors. On the other hand, positivity of surgical margins, a very important parameter related to the outcome of patients submitted to radical prostatectomy, mainly in organ-confined tumors $(16,17)$, was similar for both groups; $22.2 \%$ and $24.3 \%$ in groups 1 and 2 , respectively.

This is the first study to our knowledge to show histological characteristics of radical prostatectomy specimens in men submitted to surgery to treat adenocarcinoma where was necessary to use IHC for final diagnosis.

\section{CONCLUSION}

Our data show that the usage of IHC did not lead to diagnosis of insignificant tumors, as demonstrated by the study of the radical prostatectomy specimens that had similar pathological stage and positive surgical margins rates. Therefore, our results show that this modality should be routinely used to evaluate a borderline biopsy and ASAP cases.

\section{CONFLICT OF INTEREST}

None declared.

\section{REFERENCES}

1. Epstein JI, Herawi M: Prostate needle biopsies containing prostatic intraepithelial neoplasia or atypical foci suspicious for carcinoma: implications for patient care. J Urol. 2006; 175: 820-34.

2. Leite KR, Mitteldorf CA, Camara-Lopes LH: Repeat prostate biopsies following diagnoses of prostate intraepithelial neoplasia and atypical small gland proliferation. Int Braz J Urol. 2005; 31: 131-6.

3. Schlesinger C, Bostwick DG, Iczkowski KA: Highgrade prostatic intraepithelial neoplasia and atypical small acinar proliferation: predictive value for cancer in current practice. Am J Surg Pathol. 2005; 29: 1201-7. Erratum in: Am J Surg Pathol. 2005; 29: 1548.

4. Hoedemaeker RF, Kranse R, Rietbergen JB, Kruger AE, Schröder FH, van der Kwast TH: Evaluation of prostate needle biopsies in a population-based screening study: the impact of borderline lesions. Cancer. 1999; 85: 145-52.

5. Iczkowski KA, Bassler TJ, Schwob VS, Bassler IC, Kunnel BS, Orozco RE, et al.: Diagnosis of "suspicious for malignancy" in prostate biopsies: predictive value for cancer. Urology. 1998; 51: 749-57; discussion 757-8.

6. Gown AM, Vogel AM: Monoclonal antibodies to human intermediate filament proteins. II. Distribution of filament proteins in normal human tissues. Am J Pathol. 1984; 114: 309-21.

7. Brawer MK, Peehl DM, Stamey TA, Bostwick DG: Keratin immunoreactivity in the benign and neoplastic human prostate. Cancer Res. 1985; 45: 3663-7. 
8. Hedrick L, Epstein JI: Use of keratin 903 as an adjunct in the diagnosis of prostate carcinoma. Am J Surg Pathol. 1989; 13: 389-96.

9. O’Malley FP, Grignon DJ, Shum DT: Usefulness of immunoperoxidase staining with high-molecular-weight cytokeratin in the differential diagnosis of small-acinar lesions of the prostate gland. Virchows Arch A Pathol Anat Histopathol. 1990; 417: 191-6.

10. Wojno KJ, Epstein JI: The utility of basal cell-specific anti-cytokeratin antibody (34 beta E12) in the diagnosis of prostate cancer. A review of 228 cases. Am J Surg Pathol. 1995; 19: 251-60.

11. Shah RB, Zhou M, LeBlanc M, Snyder M, Rubin MA: Comparison of the basal cell-specific markers, $34 \mathrm{betaE} 12$ and p63, in the diagnosis of prostate cancer. Am J Surg Pathol. 2002; 26: 1161-8.

12. Barbareschi M, Pecciarini L, Cangi MG, Macrì E, Rizzo A, Viale G, et al.: p63, a p53 homologue, is a selective nuclear marker of myoepithelial cells of the human breast. Am J Surg Pathol. 2001; 25: 1054-60.

Correspondence address:

Dr. Katia Ramos Moreira Leite

Rua Desembargador Eliseu Guilherme 69

São Paulo, SP, 04004-030, Brazil

Fax: + 5511 3231-2249

E-mail: katiaramos@uol.com.br

\section{EDITORIAL COMMENT}

Immunohistochemistry (IHC) for $34 \beta E 12$ and p63 is at present a diagnostic standard for determining the presence of prostate cancer. It is also used to discriminate cancer from mimic cancer, when the definite diagnosis is difficult with conventional microscopic examinations; however, second biopsy is frequently recommended in practice. Indeed, $34-60 \%$ patients showing atypical small acinar proliferation (ASAP) in the primary biopsies were diagnosed with prostate cancer in repeat biopsy sessions $(1,2)$.
13. Signoretti S, Waltregny D, Dilks J, Isaac B, Lin D, Garraway L, et al.: p63 is a prostate basal cell marker and is required for prostate development. Am J Pathol. 2000; 157: 1769-75.

14. Humphrey PA, Vollmer RT: Percentage carcinoma as a measure of prostatic tumor size in radical prostatectomy tissues. Mod Pathol. 1997; 10: 326-33.

15. Guzzo TJ, Vira MA, Neway W, Hwang WT, Tomaszewski J, VanArsdalen K, et al.: Minimal tumor volume may provide additional prognostic information in good performance patients after radical prostatectomy. Urology. 2007; 69: 1147-51.

16. Psutka SD, Feldman AS, Rodin S, Wu CL, McDougal WS: Positive surgical margins do not affect recurrence in patients with T3a prostate cancer. J Urol. 2009; 181 (4Suppl): 776 \#abstract 288.

17. Perez D, Shental J, Israel A, Salomon L, Abbou CC: Influence of positive surgical margins on adjuvant treatment after radical prostatectomy. J Urol. 2009; 181 (4 Suppl): 776 \#abstract 2138.

Accepted after revision: February 18, 2010

As the authors stressed in the present paper, few studies have intentionally examined surgical specimens in patients with prostate cancer, who were primarily diagnosed with so-called atypical glands in previous biopsy specimens. Also, recent biopsy protocols such as multi-cores or saturation method has lead to an increase of ASAP (3). The authors elaborated patients' demographics as well as radical prostatectomy specimens, of which preoperative diagnosis in biopsy cores required 34ßE12 and p63 
IHC, to underscore the characteristics and outcome of this type of prostate cancer.

It is of interest that the patients in the IHCrequired group were younger, had lower Gleason score and lower fraction with Gleason pattern 4, and had smaller tumor foci, compared with those in the IHC-unnecessary group. These facts may be relevant to lead-time bias in patients examined during different era with a different screening protocol, or simply based on earlier disease in younger patients. Although pathological T-stage and positive surgical margin rates were not statistically different between the two groups, the difference in patients' number between them possibly explains this contradiction. Also, the IHC-required group was considered to include goodrisk cases, while the fraction of patients diagnosed with insignificant cancer was not large (7.4\%). Positive surgical margin cases were distributed uniformly between the IHC-required and IHC-unnecessary groups, suggesting that $34 \beta \mathrm{E} 12$ and p63 IHC was useful as a preoperative diagnostics even for patients showing equivocal results in biopsy specimens with routine histology.

\section{EDITORIAL COMMENT}

This study was carried out in order to investigate the value of immunohistochemstry (IHC) in borderline pathological prostate cancer cases. Immunostaining has gained an important role in the evaluation of borderline biopsy cases, especially when high-grade prostate intraepithelial neoplasia (HGPIN) and atypical small acinar proliferation (ASAP) are present. The predictive values of ASAP and HPGIN for cancer detection on repeat biopsies are 39 and $23 \%$, respectively (1). Usually, the presence of ASAP in the initial biopsy tissue requires re-biopsy within 6-12 months considering other clinical features (age, comorbidities etc.). Although this topic has not been sufficiently discussed in the literature, it may have a significant impact on patient management. It has been previously recommended that a second biopsy should

\section{REFERENCES}

1. Schlesinger C, Bostwick DG, Iczkowski KA: Highgrade prostatic intraepithelial neoplasia and atypical small acinar proliferation: predictive value for cancer in current practice. Am J Surg Pathol. 2005; 29: 12017. Erratum in: Am J Surg Pathol. 2005; 29: 1548.

2. Epstein JI, Herawi M: Prostate needle biopsies containing prostatic intraepithelial neoplasia or atypical foci suspicious for carcinoma: implications for patient care. J Urol. 2006; 175: 820-34.

3. Ploussard G, Plennevaux G, Allory Y, Salomon L, Azoulay S, Vordos D, et al.: High-grade prostatic intraepithelial neoplasia and atypical small acinar proliferation on initial 21-core extended biopsy scheme: incidence and implications for patient care and surveillance. World J Urol. 2009; 27: 587-92.

Dr. Noboru Hara

Division of Urology

Dep. of Regenerative and Transplant Medicine

Graduate School of Medical and Dental Sciences

Niigata University, Niigata, Japan

E-mail:harasho@med.niigata-u.ac.jp

include extensive sampling of the initial atypical site as well as adjacent ipsilateral and contralateral sites with routine extended schemes. However, extensive transrectal sampling may increase the risk of infection (2). Herein the authors demonstrate that imunohistochemical approach, using monoclonal antibody anti-high molecular weight cytokeratin and p63, may assist in a more accurate diagnosis of ASAP and, therefore, may obviate the need for re-biopsies with the potential complications. The main benefit from this study should be related to diagnosis and pretreatment judgment.

This study shows comparable tumor stage in both study groups (radical prostatectomy after IHC diagnosis and control) and recommends the inclusion of IHC in ASAP cases work-up. 
This study contributes to our daily clinical practice and may have major impact on our judgment in borderline prostate biopsy cases. Similar studies evaluating novel methods to enhance biopsy-based diagnosis accuracy should be encouraged in view of the intriguing concept of active surveillance. This study also leads to a yet another question - does active or passive surveillance miss cases of significant tumors that should be treated more aggressively? Future studies are warranted to answer this question.

\section{REFERENCES}

1. Iczkowski KA: Current prostate biopsy interpretation: criteria for cancer, atypical small acinar proliferation, high-grade prostatic intraepithelial neoplasia, and use of immunostains. Arch Pathol Lab Med. 2006; 130: 835-43.

2. Epstein JI, Herawi M. Prostate needle biopsies containing prostatic intraepithelial neoplasia or atypical foci suspicious for carcinoma: implications for patient care. J Urol. 2006; 175: 820-34.

Dr. Avraham Shtricker

The Sackler School of Medicine

Tel Aviv University

Tel Aviv, Israel

E-mail: shtrickera@hotmail.com

\title{
EDITORIAL COMMENT
}

Authors compared the pathologic stage between radical prostatectomy cases performed in patients for which cancer was diagnosed with the help of combined $34 \beta E 12$ and $p 63$ cocktail IHC $(n=27)$ or not $(n=1040)$. Their results showed that there was no overdiagnosis of prostate cancer with any stage $\mathrm{pT} 0$ after radical prostatectomy, with only $7.4 \%$ of cases classified as clinically insignificant. This shows the interest of IHC staining and the quality of the pathologist reading.

Pathologists frequently use immunohistochemistry to enhance their diagnostic capabilities in order to avoid rebiopsies in cases of diagnosis difficulty, which is a frequent situation in biopsy reading. I would make 2 comments:

1) Recent studies recommend not to use the ASAP definition but atypical foci

2) It was also demonstrated that a different IHC of a p63/alpha-methyl-CoA-racemase (p504s) cocktail in case of atypical foci in the prostate has a diagnostic utility (1-3).

Authors did not use this p504s in their IHC study. It may be discussed whether the addition of the p504s is superior or not to the $34 \beta \mathrm{E} 12$ and $\mathrm{p} 63$ cocktail authors used.

\section{REFERENCES}

1. Molinié V, Fromont G, Sibony M, Vieillefond A, Vassiliu V, Cochand-Priollet B, et al.: Diagnostic utility of a p63/alpha-methyl-CoA-racemase (p504s) cocktail in atypical foci in the prostate. Mod Pathol. 2004; 17: 1180-90.

2. Iczkowski KA, MacLennan GT, Bostwick DG: Atypical small acinar proliferation suspicious for malignancy in prostate needle biopsies: clinical significance in 33 cases. Am J Surg Pathol. 1997; 21: 1489-95.

3. Iczkowski KA: Current prostate biopsy interpretation: criteria for cancer, atypical small acinar proliferation, high-grade prostatic intraepithelial neoplasia, and use of immunostains. Arch Pathol Lab Med. 2006; 130: 835-43.

\author{
Dr. Arnauld Villers \\ Service d'Urologie \\ Hôpital HURIEZ, CHRU \\ Lille, France \\ E-mail:arnauld.villers@wanadoo.fr
}




\section{REPLY BY THE AUTHORS}

\section{To Dr. Arnauld Villers Comment}

ASAP is a term that has been discussed in uropathology meetings, and some pathologists argument that the suspicious gland is not always small, so it should be called atypical focus. ASAP was a very good term coined to describe doubtful lesions, and has been used for a long time. It means for us, pathologists, the presence of a small focus of atypical glands, not necessarily small, highly suspicious for cancer and help pathologists and urologists to communicate. Also, used as a keyword facilitates the search in the literature, whereas atypical has a profuse meaning. Concerning the use of alpha-methyl-CoA-racemase (p504s), it has been shown that it stains number of benign prostate glands, periurethral glands and mimics of prostate cancer (1), increases the cost and help the final decision in only $50 \%$ of cases (2).

\section{REFERENCES}

1. Gologan A, Bastacky S, McHale T, Yu J, Cai C, Monzon-Bordonaba F, Dhir R: Age-associated changes in alpha-methyl CoA racemase (AMACR) expression in nonneoplastic prostatic tissues. Am J Surg Pathol. 2005; 29: 1435-41.

2. Zhou M, Aydin H, Kanane H, Epstein JI: How often does alpha-methylacyl-CoA-racemase contribute to resolving an atypical diagnosis on prostate needle biopsy beyond that provided by basal cell markers? Am J Surg Pathol. 2004; 28: 239-43.

The Authors 